\title{
Two-electron aromatics containing three and four adjacent boron atoms*
}

\author{
C. Präsang ${ }^{1}$, A. Mlodzianowska ${ }^{1}$, G. Geiseler ${ }^{1}$, W. Massa ${ }^{1}$, \\ M. Hofmann ${ }^{2}$, and A. Berndt ${ }^{1, \neq}$ \\ ${ }^{1}$ Fachbereich Chemie der Philipps-Universität, 35032 Marburg, Germany; \\ ${ }^{2}$ Anorganisch-Chemisches Institut der Universität Heidelberg, Im Neuenheimer \\ Feld 270, 69120 Heidelberg, Germany
}

\begin{abstract}
A two-electron aromatic bis(tris-trimethylsilylmethylene)-substituted tetraborane(4) was found to be a useful precursor for the synthesis of two-electron aromatic tetraboranes(6), triboracyclopropanates, as well as tetraboranes(6) distorted toward triboracyclopropanates with boryl bridges. Bishomo two-electron aromatics with a borata bridge and a protonated borata bridge, respectively, are also presented.
\end{abstract}

\section{INTRODUCTION}

Two-electron aromatics of types I-III [1-3] as well as those of types V-VII [4-6] are known experimentally, IV [7] and VIII [8] with three and four adjacent boron atoms, respectively, only from computations. The centers of all of these aromatics are connected by classical two-center-twoelectron $(2 \mathrm{c} 2 \mathrm{e}) \sigma$-bonds. Two-electron aromatics with nonclassical $\sigma$-bonds, i.e., $\sigma$-electrons delocalized over more than two centers, have been postulated for 1, [9] the corner-protonated form of $\mathbf{I}$, on the basis of computations as early as 1980. The isoelectronic 2u [7] was computed in 1995 to be lower in energy than the classical $2 \mathbf{u}^{*}$ by not less than $54.9 \mathrm{kcal} / \mathrm{mol}$. As a first experimental approach to compounds of type 2 , the boryl-bridged $2 \mathrm{a}$ was obtained recently by addition of 4-t-butylpyridine to the first repre-

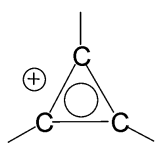

I
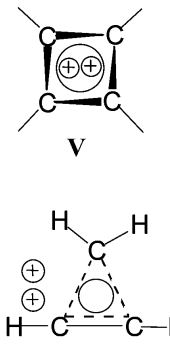

1

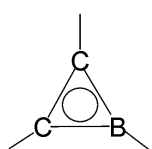

II<smiles>CB1B2C(C)B(C1C)C2C</smiles>

VI

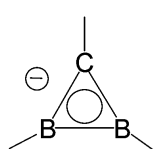

III

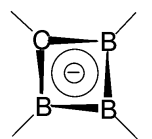

VII

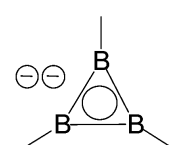

IV

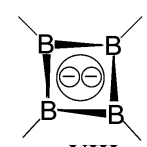

VIII

${ }^{*}$ Lecture presented at the XI ${ }^{\text {th }}$ International Meeting on Boron Chemistry (IMEBORON XI), Moscow, Russia, 28 July-2 August 2002. Other presentations are published in this issue, pp. 1157-1355.

‡Corresponding author: E-mail: berndt@ chemie.uni-marburg.de 
sentative of two-electron aromatic tetraboranes(6) with nonclassical $\sigma$-bonds, 3 [10]. A first derivative of the corresponding two-electron aromatic tetraborane(4) $\mathbf{4}$ was also presented [11].

\section{RESULTS AND DISCUSSION}

\section{Distorted rhomboid tetraboranes(4)}

The recently described $\mathbf{3 a}$ [10] can be transformed into $\mathbf{4 a}$ by reaction with lithium naphthalenide in THF at $-100{ }^{\circ} \mathrm{C}$ [12]. Tetraborane(4) $\mathbf{4 b}$, a stereoisomer of $\mathbf{4 a}$, is obtained in low yield during the synthesis of $\mathbf{3 a}$.

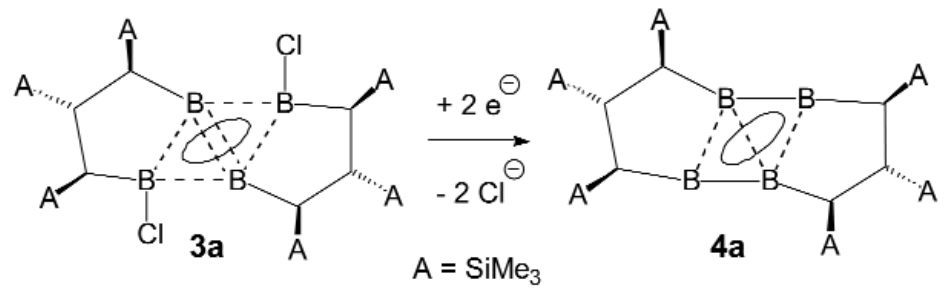

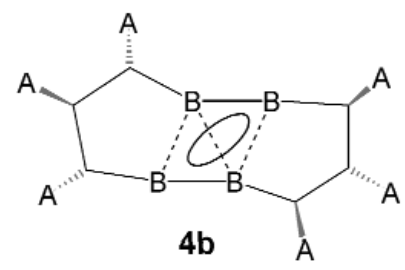

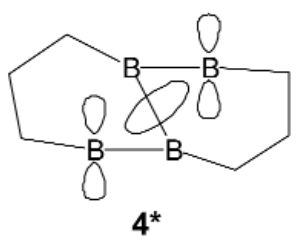
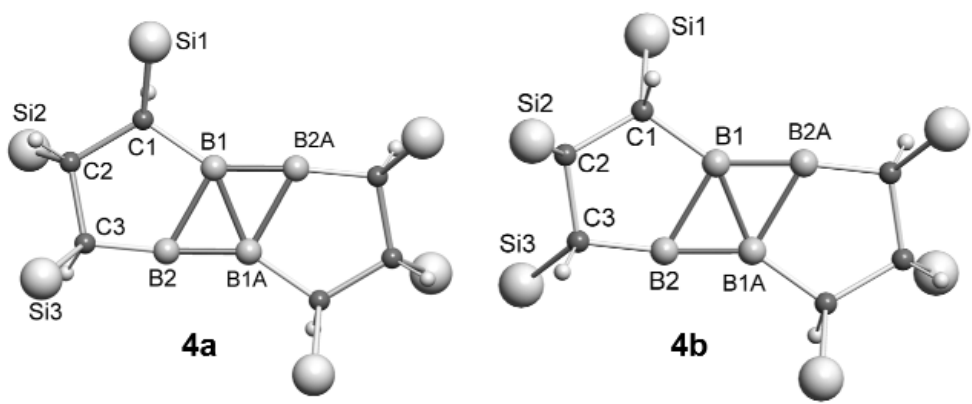

Due to a center of inversion, the $B_{4}$-ring of $\mathbf{4 b}$ is perfectly planar while that of $\mathbf{4 a}$ shows a folding angle of $177^{\circ}$. The lengths of the B-B edges of $\mathbf{4 b}[154.5(3)$ and $179.0(3) \mathrm{pm}]$ are close to those of 4a $[153.6(3), 179.1(3)]$, the short diagonal of $\mathbf{4 b}$ is slightly shorter [167.2(4) vs. 169.3(5)]. Obviously, four of the six electrons of the $\sigma$-skeleton in $\mathbf{4 a}, \mathbf{b}$ are mainly localized in the two short B-B bonds. The remaining two electrons are delocalized over the four boron centers. This can be regarded as the consequence of strong hyperconjugation between formally empty p-orbitals in the plane of the B4 ring in classical $4^{*}$ with a $\sigma$-bond along the short diagonal. The ${ }^{11} \mathrm{~B}$ NMR chemical shifts of $4 \mathbf{b}$ (32 and $121 \mathrm{ppm}$ ) are similar to those of $\mathbf{4 a}$ (33 and $125 \mathrm{ppm})$. Attempts to determine the barrier of topomerization [12] of $\mathbf{4 b}$ failed due to low thermal stability of the latter.

\section{Triboracyclopropanates by addition of nucleophiles to tetraborane(4) (4a)}

Reactions of $\mathbf{4 a}$ with lithiumamides, lithiumalkyls, or $\mathrm{NaBEt}_{3} \mathrm{H}$ lead to $\mathbf{2 b}, \mathbf{2 c}$ [13], or $\mathbf{2 d}$, respectively, addition of 4-t-butylpyridine or 4-dimethylaminopyridine yields blue and red solutions of $\mathbf{2 e}$ and $\mathbf{2 f}$, respectively. All new compounds were characterized by NMR spectroscopy as well as by X-ray structural analyses. Relevant distances in $\mathbf{2 b}-\mathbf{2 f}$ are compared in Table 1 to those computed for $\mathbf{2 g - i}$ and $\mathbf{2} \mathbf{u}$ at the B3LYP/6-31G* level. 


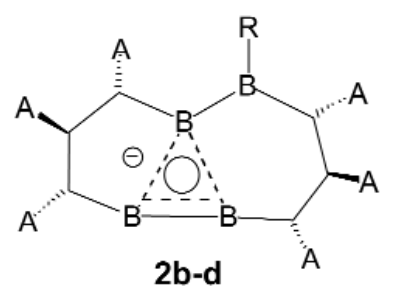

b: $\mathrm{R}=\mathrm{HNAr}\left(\mathrm{Ar}=3,5\right.$-di-t-butylphenyl) $\mathbf{c}: \mathrm{R}=\mathrm{CH}_{2} \mathrm{SiMe}_{3}$

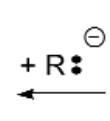

$4 a$

d: $\mathrm{R}=\mathrm{H}$

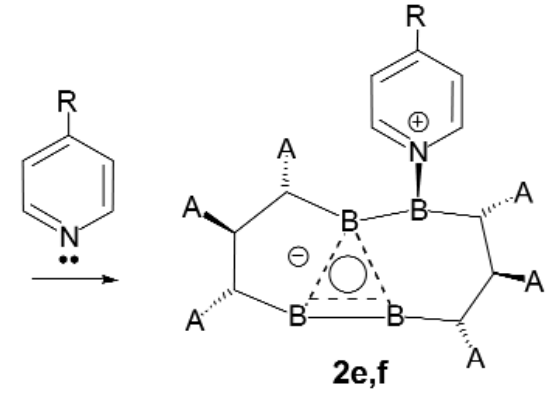

e: $\mathrm{R}=t-\mathrm{Bu} \quad$ f: $\mathrm{R}=\mathrm{NMe}_{2}$
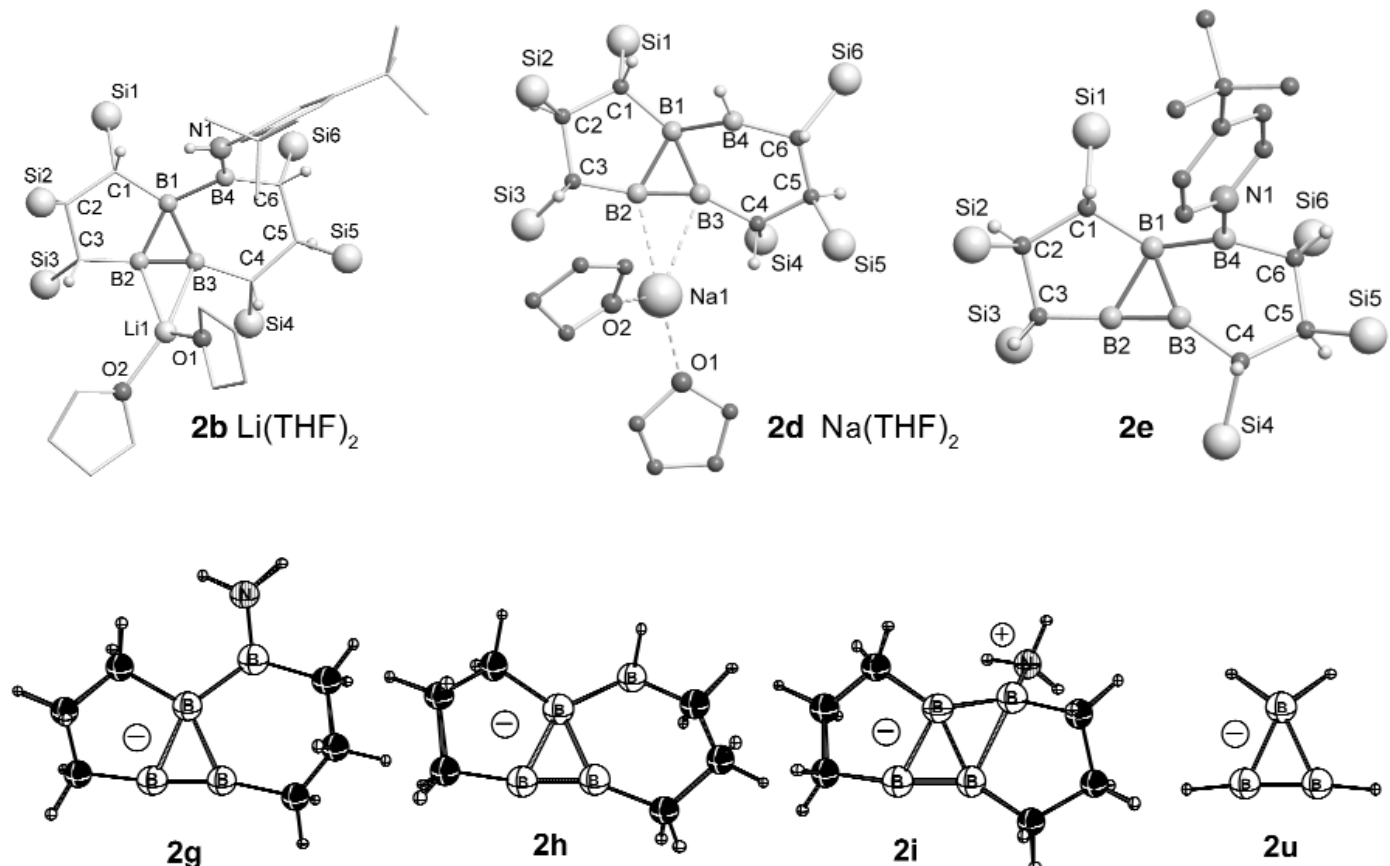

$2 \mathrm{~g}$
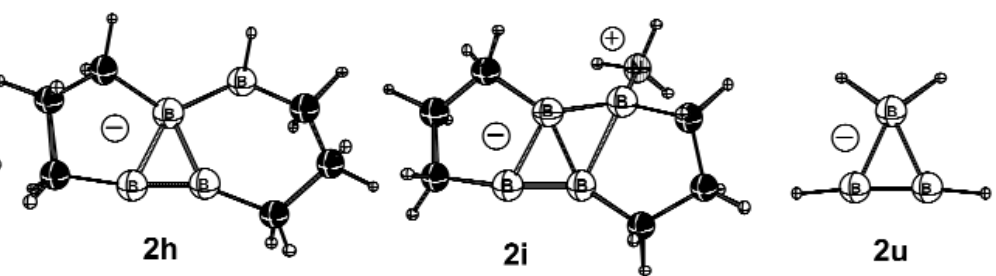

Table 1 Selected distances and angles in $\mathbf{2 b - 2 f}$ (exp.), $\mathbf{2 g - 2 i}$, and $\mathbf{2 u}$ [calc. //B3LYP/6-31G(d)].

\begin{tabular}{lccccccccc}
\hline & $\mathbf{2 b}$ & $\mathbf{2 c}$ & $\mathbf{2 d}$ & $\mathbf{2 e}$ & $\mathbf{2 f}$ & $\mathbf{2 g}$ & $\mathbf{2 h}$ & $\mathbf{2 i}$ & $\mathbf{2 u}$ \\
\hline B2-B3 & 147.4 & 148.3 & 150.3 & 153.7 & 152.7 & 147.5 & 149.4 & 152.6 & 146.8 \\
B1-B2 & 172.6 & 173.2 & 172.0 & 171.6 & 174.2 & 176.1 & 175.6 & 176.2 & 172.9 \\
B1-B3 & 172.1 & 172.5 & 164.8 & 168.5 & 169.4 & 173.3 & 171.1 & 169.4 & 172.9 \\
B1-B4 & 171.2 & 172.1 & 166.3 & 162.9 & 163.1 & 170.2 & 164.5 & 159.8 & - \\
B3-B4 & 245.8 & 250.5 & 205.3 & 192.0 & 200.2 & 264.1 & 233.0 & 195.2 & - \\
B2, B3, B1, B4 & 167.4 & 154.4 & 146.2 & 177.4 & 170.4 & 171.6 & 170.9 & 172.3 & - \\
B3, B1, B4, X & 131.0 & 151.8 & 139.8 & 109.1 & 117.3 & 162.8 & 120.8 & 111.2 & - \\
\hline
\end{tabular}

Addition of nucleophiles transforms the four-membered two-electron aromatic $\mathbf{4 a}$ into threemembered two-electron aromatics $\mathbf{2 b - 2 f}$. Compounds $\mathbf{2 b}$ and $\mathbf{2 c}$ are characterized by remarkably short B2-B3 distances of only 147.4 and 148.3 pm, respectively, the shortest B-B bonds ever observed. A (C) 2003 IUPAC, Pure and Applied Chemistry 75, 1175-1182 
corresponding B-B distance of $148.0 \mathrm{pm}$ was calculated for the prototype $\mathrm{B}_{3} \mathrm{H}_{4}{ }^{-}$anion $2 \mathbf{u}$ at MP2/6-31G* [7]. The B3-B4 distances in $\mathbf{2 b}$, 2c , and $\mathbf{2 g}$ (264, 251, and $264 \mathrm{pm}$ ) differ considerably from those in $\mathbf{2 d}, \mathbf{2 e}$, and $\mathbf{2 f}(205,192$, and $200 \mathrm{pm})$ which are close to that calculated for $\mathbf{2 i}$ (195.2 ppm). These findings can be explained by a strong interaction of the formally empty p-orbital at B4 in $\mathbf{2 d}, \mathbf{2 e}$, and $\mathbf{2 f}$ with the 3c2e $\sigma$-bond connecting B1, B2, and B3. This p-orbital is oriented close to orthogonal with respect to the axes of the p-orbitals of the aromatic $\pi$-system in $\mathbf{2 e}$ and $\mathbf{2 f}$ as seen from their B3, B1, B4, N torsional angles of 109 and $117^{\circ}$. The corresponding angles are considerably larger in $\mathbf{2 b}, \mathbf{2 d}$, and $\mathbf{2 c}\left(\mathrm{B} 3, \mathrm{~B} 1, \mathrm{~B} 4, \mathrm{X}=131,140\right.$, and $\left.152^{\circ}\right)$. The interaction of the p-orbital at B4 with the three-membered ring is considerably reduced in $\mathbf{2 b}$ by the amino donor at B4. This argumentation is supported by the even larger B3-B4 distance of $268 \mathrm{pm}$ in a dianion [13] formally carrying a carbanionic donor at B4. In 2c the electronic effect of the alkyl substituent as well as steric hindrance probably reduce the interaction discussed above. Thus, strong interaction between an exocyclic boryl boron center and a negatively charged triboracyclopropane ring with a nonclassical $\sigma$-skeleton takes place in $\mathbf{2 e}, \mathbf{2 f}$, and $\mathbf{2 i}$. This interaction is considerably reduced in $\mathbf{2 b}$ and $\mathbf{2 g}$ where the formally empty p-orbital at the boryl boron is partly filled by strong donor substituents. Alternatively, conjugation can be cancelled by adding a hydride anion to the exocyclic boron: a B3-B4 distance of $280.3 \mathrm{pm}$ is computed for $\mathbf{2 k}$. Our efforts for an experimental verification have been unsuccessful: addition of $\mathrm{NaBEt}_{3} \mathrm{H}$ to $\mathbf{2 d}$ does not lead to the desired product, but to the bishomo two-electron aromatic $\mathbf{5}$ discussed in the section "A bishomo two-electron aromatic with a borata bridge".
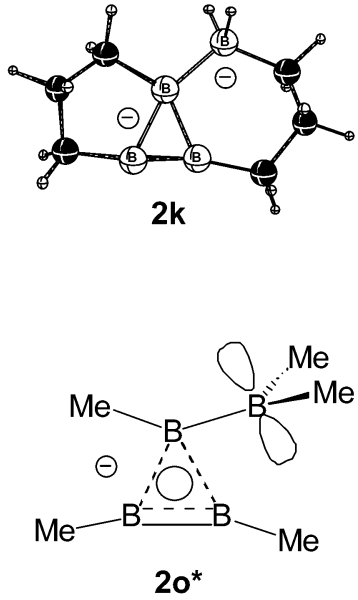
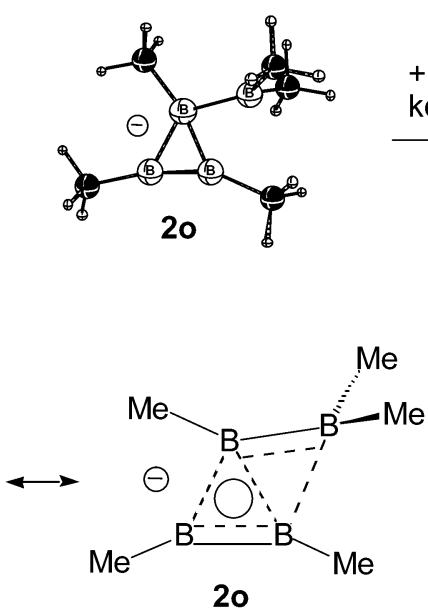
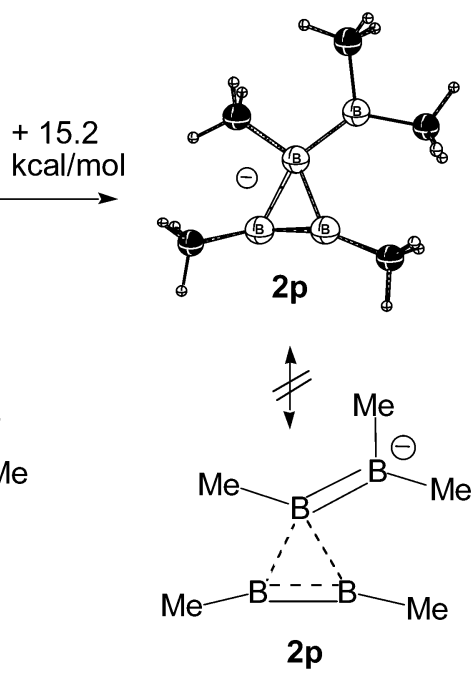

Computations on models $2 \mathbf{o}$ and $\mathbf{2 p}$ show that the orthogonal orientation of the boryl substituent is strongly preferred over the coplanar one. This observation is reminiscent of the results obtained for the dication of methylenecyclopropene [14]. In both cases, the 2e-aromatics are poor $\pi$-electron donors due to their strong aromatic stabilization [15], but strong $\sigma$-electron donors due to ring strain.

\section{Tetraboranes(6) distorted toward triboracyclopropanates with boryl bridges}

The tetraborane(6) $\mathbf{3} \mathbf{c}$ is obtained by addition of 3,5-di-t-butylaniline to $4 \mathbf{a}$. Protonation of $\mathbf{2 c}$ yields $\mathbf{3 d}$, while $\mathbf{3 e}$ is accessible from $\mathrm{Me}_{2} \mathrm{NSiMe}_{3}$ and $\mathbf{3 f}$, which can be prepared from $\mathbf{3 a}$ and $\mathrm{LiCH}_{2} \mathrm{SiMe}_{3}$. All compounds were characterized by NMR and X-ray structural analyses (see Table 2).

The geometrical details of the B1, B3, B4 triangle in 3c are similar to those of the corresponding triangle in $\mathbf{2 b}$. B4 of $\mathbf{3 c}$ is planar-tetracoordinate, while B2 shows a distorted tetrahedral coordination 


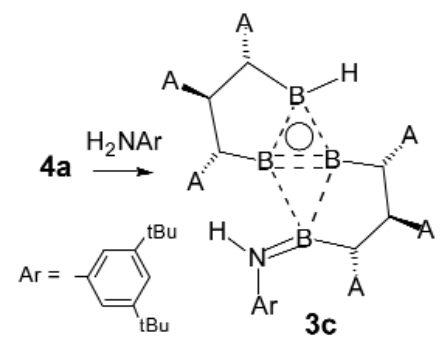

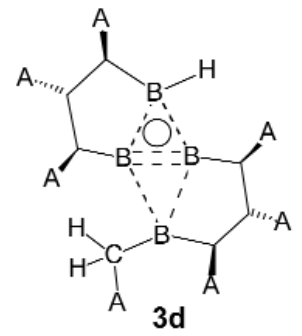

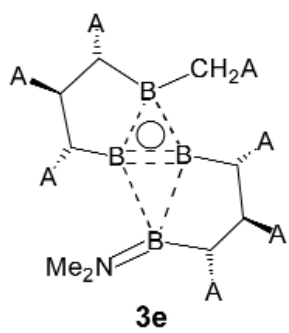

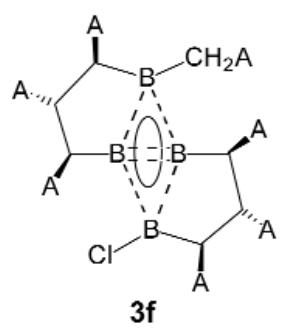
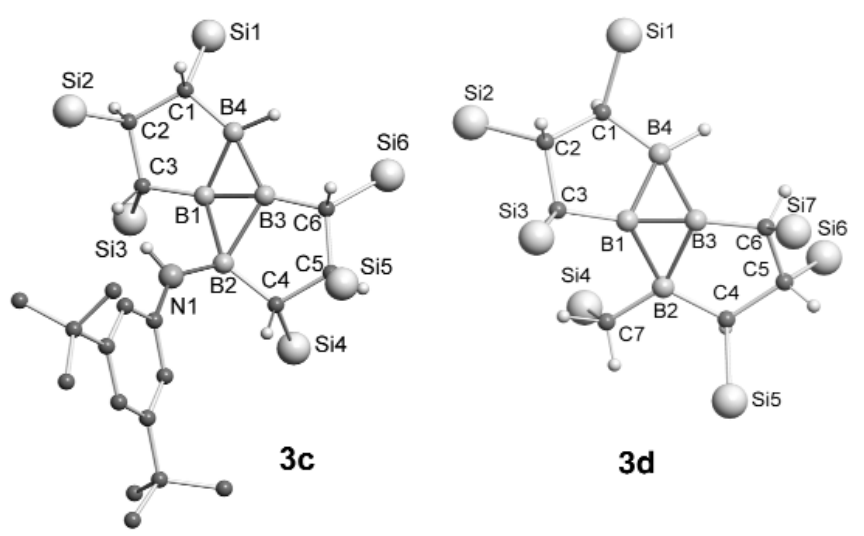

3d

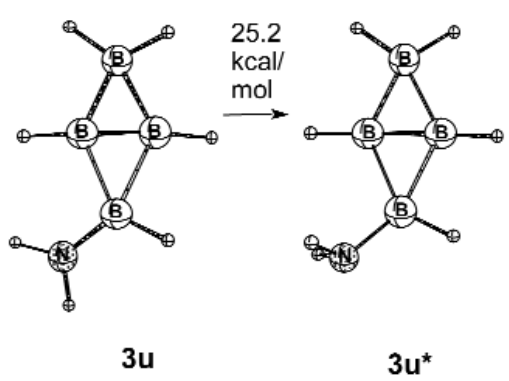

sphere and considerably longer distances to B1 and B3 than B4. Thus, $\mathbf{3 c}$ can be regarded as a two-electron aromatic with three adjacent boron atoms of type $\mathbf{2}$, where the metal cation is replaced by an aminoboryl bridge. Computed distances for the model $\mathbf{3 u}$ are close to those determined for $\mathbf{3 c}$. Obviously, the amino substituent is responsible for the distortion of the tetraboranes(6) $\mathbf{3 c}$ and $\mathbf{3 u}$ toward structures of type $\mathbf{2}$. Interestingly, a comparable distortion is computed for $\mathbf{3} \mathbf{u}^{*}$ with the lone pair at nitrogen in the $\mathrm{B}_{4} \mathrm{~N}$ plane. Steric hindrance of a trimethylsilyl substituent in $\mathbf{3 d}$ leads to a similar but less pronounced distortion compared to $\mathbf{3 c}$. In $\mathbf{3 e}$, the amino-substituted boron is tetrahedrally distorted and has a long distance to B1.

Table 2 Selected distances $[\mathrm{pm}]$ and angles $\left[{ }^{\circ}\right]$ of $\mathbf{3 c}-\mathbf{3 f}$ (exp.) and $\mathbf{3 u}$ [calc. //B3LYP/6-31G(d)].

\begin{tabular}{lcccccc}
\hline & 3c & 3u & 3d & 3e & 3f & 3u* $^{*}$ \\
\hline B1-B3 & 151.7 & 150.7 & 151.2 & 148.0 & 149.6 & 150.5 \\
B1-B4 & 169.4 & 167.5 & 173.6 & 184.5 & 183.8 & 171.0 \\
B3-B4 & 169.2 & 168.7 & 176.4 & 186.7 & 186.1 & 171.6 \\
B2-B1 & 189.5 & 180.4 & 185.0 & 200.6 & 187.1 & 179.0 \\
B2-B3 & 192.0 & 185.6 & 182.7 & 184.9 & 178.9 & 181.7 \\
B2, B1, B3, B4 & 155.0 & 180.0 & 134.5 & 119.2 & 131.0 & 180.0 \\
B3, B1, B4, X & $179.0^{\mathrm{a}}$ & $180.0^{\mathrm{a}}$ & $174^{\mathrm{a}}$ & $167.9^{\mathrm{b}}$ & $169.2^{\mathrm{b}}$ & $180.0^{\mathrm{a}}$ \\
$\mathrm{B} 3, \mathrm{~B} 1, \mathrm{~B} 2, \mathrm{Y}$ & $143.1^{\mathrm{c}}$ & $180.0^{\mathrm{c}}$ & $174.3^{\mathrm{b}}$ & $141.0^{\mathrm{c}}$ & $167.0^{\mathrm{d}}$ & $180.0^{\mathrm{c}}$ \\
\hline${ }^{\mathrm{a}} \mathrm{X}=\mathrm{H}$ & & & & & & \\
${ }^{\mathrm{b} X=\mathrm{X}}$ & & & & & & \\
${ }^{\mathrm{c}} \mathrm{Y}=\mathrm{N}$ & & & & & & \\
${ }^{\mathrm{d} X=\mathrm{Cl}}$ & & & & & &
\end{tabular}




\section{A bishomo two-electron aromatic with a borata bridge}

Addition of a hydride anion to $\mathbf{2 d}$ is a slow reaction which does not lead to a compound corresponding to $2 \mathbf{k}$ but to $\mathbf{5}$ instead. A related product $\mathbf{6}$ is obtained when $\mathbf{3 g}$ [10] is reacted with $\mathrm{NaBEt}_{3} \mathrm{H}$. Note that the stereochemistry of the trimethylsilyl substituents, which is different in the starting materials $\mathbf{2 d}$ and $\mathbf{3 g}$, is retained in the corresponding products $\mathbf{5}$ and $\mathbf{6}$.
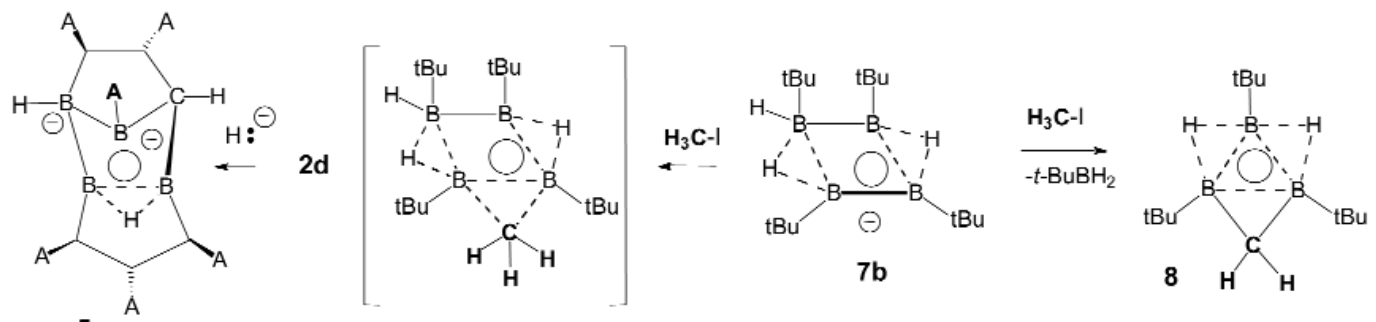

5
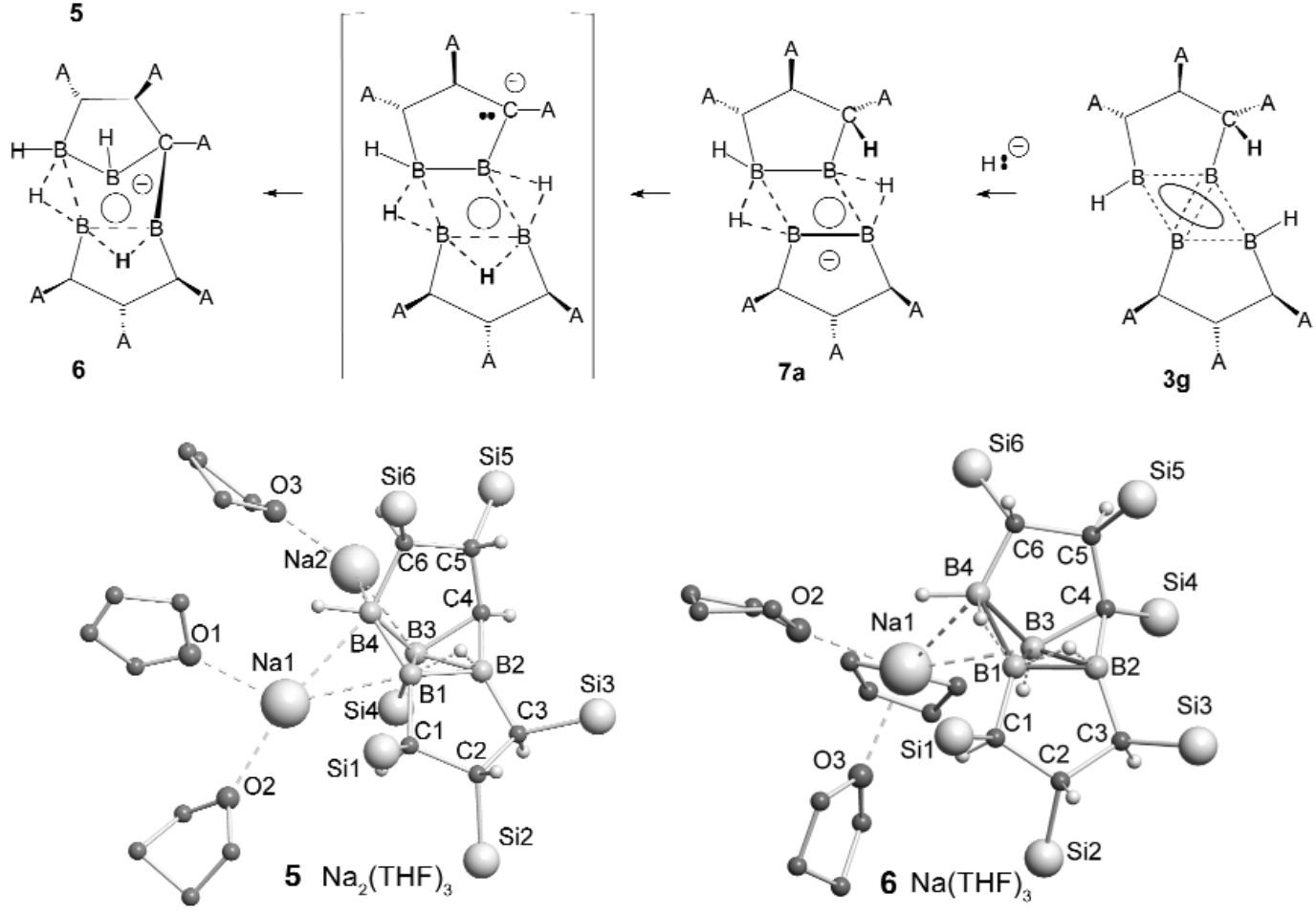

The formation of $\mathbf{6}$ can be easily explained in analogy to the transformation of Paetzold's $\mathbf{7 b}$ into 8 [16]. While 7b is first attacked by an electrophilic methyl iodide at the nucleophilic B-B bond drawn in bold, the corresponding B-B bond of $\mathbf{7 a}$ is attacked intramolecularly by a nearby proton. This generates one formal negative charge at the carbon to which it was bound. A new bond between the latter and a nearby boron forms and a bridging $\mathrm{H}$ becomes a terminal one in $\mathbf{6}$. A similar transformation involving migration of a silyl group to a boron center must take place after hydride addition to $\mathbf{2 d}$. The transannular distances B3-B1 and B3-B2 in 5 and $\mathbf{6}$ (181.8, 175.6, and 175.3, 176.4, respectively) are shorter than any observed in anionic bishomo aromatics before [17]. To the best of our knowledge, $\mathbf{5}$ is the first homoromatic molecule with a borata bridge. Known homoaromatics contain familiar methylene bridges, which are isoelectronic to borata bridges. In contrast, the protonated form of such a bridge, which is found in $\mathbf{6}$ and in $\mathbf{7 b}$, is common in arachno and hypho boranes. This kind of a homo bridge completes the series of classical and nonclassical homo bridges [17] by a link in between: while clas- 
sical and nonclassical homo bridges contain two two-center-two-electron(2c2e) bonds or one threecenter-two-electron $(3 \mathrm{c} 2 \mathrm{e})$ bond, respectively, the protonated borata bridge contains one 2c2e-bond as well as one $3 \mathrm{c} 2 \mathrm{e}-$ bond.

\section{CONCLUSION}

In this paper, we report recent results in the chemistry of two-electron aromatics with nonclassical $\sigma$-skeletons built from three and four boron atoms. Two-electron aromatic triboracyclopropanates with a boryl substituent at the tetracoordinate boron center are obtained by addition of nucleophiles to an aromatic tetraborane(4). We present representatives of a class of molecules where $\sigma \rightarrow p$ interactions are considerably stronger than $\pi \rightarrow \mathrm{p}$ interactions. The huge aromatic stabilization energy of two-electron aromatics like those of type $\mathbf{2}$ and ring strain in three-membered rings explain this unusual behavior. A strong tendency to form two-electron aromatics of type $\mathbf{2}$ is also observed in those compounds of type $\mathbf{3}$ which possess electronically or sterically active substituents. Intramolecular rearrangements of a tetraborane(6) dianion led to the first homoaromatic with a classical borata bridge.

\section{ACKNOWLEDGMENT}

We thank Deutsche Forschungsgemeinschaft (Schwerpunktprogramm Polyeder) and Fonds der Chemischen Industrie for financial support.

\section{REFERENCES}

1. R. Breslow. J. Am. Chem. Soc. 79, 5318 (1957); R. Breslow. Pure Appl. Chem. 28, 111-130 (1971).

2. J. J. Eisch, B. Shafii, J. D. Odom, A. L. Reingold. J. Am. Chem. Soc. 112, 1847-1853 (1990) and literature cited therein.

3. R. Wehrmann, H. Meyer, A. Berndt. Angew. Chem. 97, 779-781 (1985); Angew. Chem., Int. Ed. Engl. 24, 788-790 (1985).

4. G. A. Olah and G. D. Mateescu. J. Am. Chem. Soc. 92, 1430-1432 (1970); M. Bremer, P. von R. Schleyer, U. Fleischer. J. Am. Chem. Soc. 111, 1147-1148 (1989).

5. M. Hildenbrand, H. Pritzkow, W. Siebert. Angew. Chem. 97, 769-770 (1985); Angew. Chem., Int. Ed. Engl. 24, 759-760 (1985); P. H. M. Budzelaar, K. Krogh-Jespersen, T. Clark, P. von R. Schleyer. J. Am. Chem. Soc. 107, 2773-2779 (1985); M. McKee. Inorg. Chem. 39, 4206-4210 (2000), and literature cited therein.

6. Y. Sahin, C. Präsang, P. Amseis, M. Hofmann, G. Geiseler, W. Massa, A. Berndt. Angew. Chem. 115, 693-695 (2003); Angew. Chem., Int. Ed. 42, 669-671 (2003).

7. A. A. Korkin, P. von R. Schleyer, M. L. McKee. Inorg. Chem. 34, 961-977 (1995); M. L. McKee. Inorg. Chem. 38, 321-330 (1999).

8. M. J. S. Dewar and M. L. McKee. Inorg. Chem. 17, 1569-1581 (1978); A. Dreuw, N. Zint, L. S. Cederbaum. J. Am. Chem. Soc. 124, 10903-10910 (2002); Note added in proof: For a recent experimental realization of dianions of type VIII, see: W. Mesbah, C. Präsang, M. Hofmann, G. Geiseler, W. Massa, A. Berndt. Angew. Chem. 115, 1758-1760 (2003); Angew. Chem., Int. Ed. Engl. 42, 1717-1719 (2003).

9. T. Clark and R. Weiss. J. Org. Chem. 45, 1790-1794 (1980); M. W. Wong and L. Radom. J. Mol. Struct. 198, 391-402 (1989); K. Lammertsma and P. von R. Schleyer. J. Am. Chem. Soc. 112, 7935-7940 (1990).

10. C. Präsang, M. Hofmann, G. Geiseler, W. Massa, A. Berndt. Angew. Chem. 114, 1597-1599 (2002); Angew. Chem., Int. Ed. 41, 1526-1529 (2002). 
11. A. Maier, M. Hofmann, H. Pritzkow, W. Siebert. Angew. Chem. 114, 1600-1602 (2002); Angew. Chem., Int. Ed. 41, 1529-1532 (2002).

12. C. Präsang, M. Hofmann, G. Geiseler, W. Massa, A. Berndt. Angew. Chem. 115, 1079-1082 (2003); Angew. Chem., Int. Ed. Engl. 42, 1049-1052 (2003).

13. C. Präsang, A. Mlodzianowska, M. Hofmann, G. Geiseler, W. Massa, A. Berndt. Angew. Chem. 114, 3529-3531 (2002); Angew. Chem., Int. Ed. 41, 3380-3382 (2002).

14. J. Chandrasekhar and P. von R. Schleyer. J. Comput. Chem. 2, 356-360 (1981).

15. P. H. M. Budzelaar and P. von R. Schleyer. J. Am. Chem. Soc. 108, 3967-3970 (1986) and literature cited therein.

16. A. Neu, K. Radacki, P. Paetzold. Angew. Chem. 111, 1358-1360 (1999); Angew. Chem., Int. Ed. Engl. 38, 1281-1283 (1999).

17. M. Hofmann, D. Scheschkewitz, A. Ghaffari, G. Geiseler, W. Massa, H. F. Schaefer, A. Berndt, J. Mol. Model. 6, 257-271 (2000) and literature cited therein. 